\title{
Stress hyperglycaemia
}

\author{
Kathleen M Dungan, MD, \\ The Ohio State University, Columbus, OH, USA
}

Prof Susan S Braithwaite, MD, and

The University of North Carolina, Chapel Hill, NC, USA

Prof Jean-Charles Preiser, MD

Centre Hospitalier Universitaire de Liege, Belgium

\section{Abstract}

Results of randomised controlled trials of tight glycaemic control in hospital inpatients might vary with population and disease state. Individualised therapy for different hospital inpatient populations and identification of patients at risk of hyperglycaemia might be needed. One risk factor that has received much attention is the presence of pre-existing diabetes. So-called stress hyperglycaemia is usually defined as hyperglycaemia resolving spontaneously after dissipation of acute illness. The term generally refers to patients without known diabetes, although patients with diabetes might also develop stress hyperglycaemia — a fact overlooked in many studies comparing hospital inpatients with or without diabetes. Investigators of several studies have suggested that patients with stress hyperglycaemia are at higher risk of adverse consequences than are those with pre-existing diabetes. We describe classification of stress hyperglycaemia, mechanisms of harm, and management strategies.

\section{Introduction}

Transient hyperglycaemia during severe illness in adult patients without known diabetes was thought to be harmless or even advantageous. However, results of a large randomised controlled trial ${ }^{1}$ showed clear mortality benefits from intensive insulin therapy for patients in intensive care units (ICUs), irrespective of whether a previous diagnosis of diabetes had been made. Subsequent reports ${ }^{2-8}$ in mixed medical and surgical ICUs have tempered initial enthusiasm for strict glycaemic control, mainly because of an unacceptable risk of hypoglycaemia. Such findings have triggered appeals for focused efforts to identify patients who are at high risk of hyperglycaemia-mediated harm and likely to benefit from interventions. ${ }^{9}$

Investigators of several studies suggest that patients with stress hyperglycaemia and no previous diagnosis of diabetes face worse consequences at a given severity of hyperglycaemia than do those with pre-existing diabetes. We describe challenges in identification and diagnosis of such patients, analyse the evidence that lends support to the harms of stress hyperglycaemia, review the unique causal features and proposed

Correspondence to: Kathleen M Dungan, The Ohio State University, Division of Endocrinology, Diabetes, and Metabolism, Columbus, OH 43210-1296, USA, kathleen.dungan@osumc.edu.

Contributors

KMD, SSB, and J-CP participated in the analysis and writing of this Lancet seminar and have seen and approved the final version.

Conflicts of interest

KMD has received grant support from NovoNordisk, Diramed, and Tolerx, and has consulted with Eli Lilly, Diramed, and

Glycomark. SSB and J-CP declare that they have no conflicts of interest. 
mechanisms of harm of stress hyperglycaemia, suggest management strategies, and identify areas of future study. We intend not to diminish the importance of pre-existing diabetes or chronic glycaemic control, but to draw attention to the adverse consequences or concomitant effects of acute hyperglycaemia.

\section{Diagnosis}

Stress hyperglycaemia generally refers to transient hyperglycaemia during illness and is usually restricted to patients without previous evidence of diabetes. For the purpose of this Seminar, we will discuss physical—rather than psychological—stress. However, the identification of such patients is complex. No guidelines specifically define stress hyperglycaemia. In a technical review written by the Diabetes in Hospitals Writing Committee of the American Diabetes Association (ADA),${ }^{10}$ patients are classified into one of three groups - known diabetes, newly diagnosed diabetes, and hospital-related hyperglycaemia (panel). This classification needs information from hospital follow-up that is not usually available. Change in glucose from baseline and not the absolute glucose concentration might be of value, irrespective of whether a patient has pre-existing diabetes (figure 1). Thus, we propose two diagnostic categories of stress hyperglycaemia-hospitalrelated hyperglycaemia according to the ADA consensus definition (fasting glucose $>6.9$ $\mathrm{mmol} / \mathrm{L}$ or random glucose $>11.1 \mathrm{mmol} / \mathrm{L}$ without evidence of previous diabetes), and preexisting diabetes with deterioration of preillness glycaemic control. The most appropriate cutoff point for stress hyperglycaemia in patients with pre-existing diabetes needs to be established, but certainly a patient with a well controlled $(<7 \%)$ glycosylated haemoglobin $\left(\mathrm{HbA}_{1 \mathrm{c}}\right)$ whose glucose concentration is consistently higher than the threshold defined for hospital-related hyperglycaemia would qualify.

$30 \%$ of people who have diabetes in the USA are unaware of their status ${ }^{11}$ and, therefore, many hospital inpatients with apparent stress hyperglycaemia have underlying diabetes or prediabetes (table). ${ }^{12-18}$ In an undifferentiated hospital population, results from a small study ${ }^{18}$ showed that $60 \%$ of patients with admission hyperglycaemia had confirmed diabetes at 1 year. Another study showed that nearly one in five adult inpatients had probable unrecognised diabetes-identified by an admission $\mathrm{HbA}_{1 \mathrm{c}}$ higher than $6 \cdot 1 \% .{ }^{19}$ In this study, random glucose concentrations poorly predicted elevated $\mathrm{HbA}_{1 \mathrm{c}}$, indicating the need for more sophisticated diagnostic criteria than are available.

\section{Epidemiology}

\section{Poor outcomes related to stress hyperglycaemia}

Researchers of intravenous insulin therapy have not specifically compared patients with and without stress hyperglycaemia in prospective controlled studies. ${ }^{1-6}$ Other investigators ${ }^{20}$ exclude patients without known diabetes altogether. With the exception of a few randomised trials, most data are observational and drawn from ICUs or patients with acute myocardial or cerebrovascular events. One retrospective review ${ }^{21}$ of 1886 unselected hospital inpatients was stratified according to whether patients had normoglycaemia, pre-existing diabetes, or newly diagnosed hyperglycaemia (fasting glucose $>7 \mathrm{mmol} / \mathrm{L}$ or random glucose $>11 \cdot 1$ $\mathrm{mmol} / \mathrm{L}$ on two separate occasions). Compared with patients with normoglycaemia, after adjustment for age, body-mass index, sex, hyper tension, coronary artery disease, infection, renal failure, and ICU admission, mortality was 18.3 times higher in patients with newly diagnosed hyperglycaemia ( $\mathrm{p}<0.05)$, but only 2.7 times higher in those with known diabetes $(\mathrm{p}<0.05)$. This study did not distinguish between a new diagnosis of diabetes and transient stress hyperglycaemia. 
However, a relation between short-term glycaemic control and hospital outcomes has been identified. ${ }^{19}$ Patients with hyperglycaemia without known diabetes who were critically ill $^{22-26}$ or had acute coronary or cerebro-vascular ${ }^{1,13,27-32}$ events were shown to have increased risk of mortality, although patients who were hyperglycaemic with known diabetes did not. Increased mortality was also reported in hyperglycaemic inpatients with or without diabetes who had acute myocardial infarction or acute coronary syndrome, ${ }^{33-40}$ or cerebrovascular accident. ${ }^{41}$ Other studies ${ }^{41-45}$ reported no rise in risk related to hyperglycaemia in inpatients in ICUs, or in patients with acute coronary syndrome, or cerebrovascular accident.

\section{Stress hyperglycaemia in ICUs}

In posthoc analysis, data from a large randomised controlled trial ${ }^{46}$ of intensive insulin therapy in a surgical ICU suggest that patients with a previous diagnosis of diabetes were at lower risk of mortality than were those without or newly diagnosed with diabetes (odds ratio [OR] $0 \cdot 356,95 \%$ CI $0 \cdot 158-0 \cdot 803, \mathrm{p}=0 \cdot 01$ ). Posthoc analysis of the counterpart to this study in a medical ICU showed a reduction in mortality only in patients needing an ICU stay of 3 days or longer, and seemingly only in patients with newly discovered hyperglycaemia (11.5\% reduction in mortality in patients with new hyperglycaemia $v s 1.8 \%$ increase in mortality with those with known diabetes). ${ }^{2}$ In a pooled analysis of both trials, patients with diabetes achieved no survival benefit, although the number of patients with known diabetes was small. $^{22}$

In other randomised studies, ${ }^{3,6,8}$ results were stratified according to the presence of preexisting diabetes. Investigators of a small $(\mathrm{n}=523)^{6}$ single-centre study reported no benefit of intensive intravenous insulin therapy with a mean glucose target of $4.4-6 \cdot 1 \mathrm{mmol} / \mathrm{L}$ compared with a target of $10-11.1 \mathrm{mmol} / \mathrm{L}$. This study was powered to detect an $8 \%$ absolute risk reduction. No difference in outcomes between patients with or without diabetes was identified. Investigators of a multicentre randomised controlled study of patients with sepsis noted outcomes did not differ between those with or without diabetes treated with intensive insulin therapy. However, this study was stopped before enrolment was completed largely because of frequent hypoglycaemia. ${ }^{3}$

A pivotal, large, multicentre randomised controlled trial (NICE-SUGAR) ${ }^{8}$ comparing conventional $(<10 \mathrm{mmol} / \mathrm{L})$ versus tight $(4.5-6 \cdot 0 \mathrm{mmol} / \mathrm{L})$ glycaemic control using intravenous insulin infusions in ICU patients showed increased mortality for patients in the intensive arm (OR 1.14, 95\% CI 1.02-1·28, $\mathrm{p}=0.02)$. The treatment effect did not differ between surgical and non-surgical patients, nor was a difference observed between patients with or without known diabetes.

Other non-randomised or observational studies provide less robust data than does the NICESUGAR trial, but deserve mention because they attempt to identify patients with stress hyperglycaemica. In a mixed surgical $(n=676)$, medical $(n=1856)$, and trauma $(n=134)$ ICU, outcomes in patients with diabetes $(n=532)$ were compared with those in patients without known diabetes after implementation of a moderately tight glycaemic control protocol (target blood glucose concentrations $6.9 \mathrm{mmol} / \mathrm{L}$ ). ${ }^{42}$ Mortality was significantly reduced in non-diabetic patients but not in those with known diabetes. Furthermore, in patients without diabetes, mortality began to rise when mean glucose concentration exceeded $7.8 \mathrm{mmol} / \mathrm{L}$ in patients without diabetes, whereas in patients with diabetes this threshold was $10 \mathrm{mmol} / \mathrm{L}$.

Several observational studies have assessed whether patients with stress hyperglycaemia have a high risk of poor outcomes. A large observational study of 728 patients with diabetes and 4218 patients without diabetes established that at any mean ICU glucose concentration, ICU (but not hospital) mortality is greater (up to nearly four times) in patients without 
diabetes than in those with the disorder, ${ }^{23}$ even after adjustment for disease severity (Acute Physiology and Chronic Health Evaluation II score). In a mixed ICU sample of 2826 patients, those without diabetes who needed treatment for hyperglycaemia had higher sequential organ failure assessment (SOFA) scores, greater hospital length of stay ( $8.0 \mathrm{vs} 6.7$ days, $\mathrm{p}<0.001)$, and higher mortality rates $(10 \%$ vs $6 \%, \mathrm{p}<0.01)$ than did patients with known diabetes, despite lower median glucose and adjustment for severity of illness and other covariates. ${ }^{24}$ By contrast, patients with the disorder had the same death rate as normoglycaemic non-diabetic patients (6\% vs 5\%), despite higher SOFA scores and median glucose values. The high mortality rate in hyperglycaemic patients without known diabetes and absence of relation of hyperglycaemia to mortality in patients with diabetes was also reported in mixed ICU populations ${ }^{25}$ and in those with severe sepsis. ${ }^{26}$ However, not all results from ICU studies show a high risk of mortality related to acute hyperglycaemia. ${ }^{43}$

\section{Cardiovascular disease and stroke}

The relation between newly discovered hyperglycaemia and mortality in patients presenting with acute myocardial infarction or acute coronary syndrome has been investigated. Unfortunately, most studies rely on glucose concentrations at admission to identify stress hyperglycaemia. In a meta-analysis, ${ }^{47}$ the pooled unadjusted relative risk (RR) of in-hospital mortality after myocardial infarction in 1856 patients without diabetes who had stress hyperglycaemia at admission was 3.9 (95\% CI 2.9-5.4) compared with normoglycaemic non-diabetic patients. By comparison, the risk of death in 688 hyper glycaemic patients with diabetes was 1.7 (95\% CI 1.2-2.4) relative to normoglycaemic patient with diabetes.

Other studies support these findings. In more than 160000 patients admitted with acute myocardial infarction, glucose concentration at admission was associated with a steep rise in 30-day mortality for those without known diabetes: for glucose concentrations of 6.1-7.8 $\mathrm{mmol} / \mathrm{L}$ on admission, OR $1 \cdot 17$, (95\% CI $1 \cdot 11-1 \cdot 24) ; 13.3 \mathrm{mmol} / \mathrm{L}$ or more, OR 1.87 , (95\% CI 1.75-2.00) ${ }^{48}$ However, for patients with established diabetes, mortality rose only at the highest glucose concentration (>13.3 mmol/L OR 1.32, 95\% CI 1.17-1.50). Discrepancies between studies might be explained in part by the length of follow-up-the association between diabetes status and mortality strengthened as the length of follow-up increased. With longer follow-up, the assocation between diabetes and mortality was significant, but the association with stress hyperglycaemia became non-significant. ${ }^{33,34}$

Another study ${ }^{26}$ investigated the role of acute and chronic hyperglycaemia in 827 patients with diabetes, 324 of whom had at least two $\mathrm{HbA}_{1 \mathrm{c}}$ measurements in the previous 2 years. Glucose concentrations at admission in the third $(2 \cdot 84 \mathrm{mmol} / \mathrm{L}, 95 \%$ CI $1 \cdot 04-7 \cdot 76, \mathrm{p}=0 \cdot 04)$ or fourth $(5.03 \mathrm{mmol} / \mathrm{L}, 95 \% \mathrm{CI} 1 \cdot 90-13 \cdot 26, \mathrm{p}=0 \cdot 001)$ quartiles independently predicted inhospital mortality after acute myocardial infarction. However, mortality did not differ much between quartiles of $\mathrm{HbA}_{1 \mathrm{c}}$. Results of another study ${ }^{49}$ confirmed no association between mortality and $\mathrm{HbA}_{1 \mathrm{c}}$, thus drawing attention to the potential importance of acute hyperglycaemia over chronic hyperglycaemia in hospital inpatients with acute myocardial infarction.

A retrospective analysis ${ }^{50}$ of 433 patients after stroke established that blood glucose concentrations higher than $10 \mathrm{mmol} / \mathrm{L}$ at admission $(\mathrm{OR}=2 \cdot 1,95 \% \mathrm{CI} 1 \cdot 1-4 \cdot 6, \mathrm{p}=0 \cdot 02)$, but not diabetes itself, was an independent predictor of dependency 1 year after first-ever stroke. A meta-analysis ${ }^{51}$ showed that in patients without diabetes, stress hyperglycaemia (definition varied by study) was associated with a high risk of mortality after stroke (pooled RR 3.07, 95\% CI 2.50-3.79). However, this was not true for patients with diabetes (pooled RR $1 \cdot 30,95 \%$ CI 0.49-3.43). In further studies, ${ }^{31,32,52}$ Glucose concentration on admission was associated with higher mortality rates in patients without a history of diabetes than in 
those with a history of diabetes-both for ischaemic stroke and intracranial haemorrhage. This finding was not confirmed in another study. ${ }^{45}$

In a prospective observational analysis ${ }^{43}$ of 262 patients with stroke, researchers used a normal fructosamine and to identify those with transient hyperglycaemia. $\mathrm{HbA}_{1 \mathrm{c}}$ Patients with transient hyperglycaemia had worse stroke severity scores than did those with either known diabetes or normoglycaemia. Furthermore, 30-day mortality was higher in patients with transient hyperglycaemia than in those with normoglycaemia $(27.4 \%$ vs $12.7 \%$, $\mathrm{p}=0 \cdot 01$ ), but no significant difference between patients with diabetes $(16 \cdot 2 \%)$ and normoglycaemia was reported.

\section{Surgery}

The first Leuven study ${ }^{1}$ consisted largely of postsurgical patients, two-thirds of whom had cardio thoracic surgery. Because patients with no history of diabetes benefited most from intensive insulin therapy, the same could be true for the subset of post cardiothoracic surgery patients. However, a prospective study ${ }^{20}$ with historical controls showed reductions in mortality, hospital length of stay, and surgicalsite infections after cardiothoracic surgery in patients with diabetes who received intensive insulin therapy. By contrast with the Leuven study, in the Furnary study ${ }^{53}$ patients with transient hyperglycaemia were excluded, indicating that patients with diabetes also benefit from glycaemic control. This finding seems to be in agreement with another study. ${ }^{54}$

Chronic hyperglycaemia in the perioperative setting also seems to be harmful, affecting the rate of postoperative infections and neurological outcomes. ${ }^{55,56} \mathrm{~A}$ meta-analysis ${ }^{57}$ of 34 trials showed that perioperative insulin infusion reduces mortality but increases rates of hypoglycaemia. However, researchers calculated that the available mortality data were too few to reliably detect a plausible treatment effect, and that the presence of diabetes did not affect outcomes. Thus, hyperglycaemia in patients with or without diabetes could adversely affect outcomes after surgery.

Stress hyperglycaemia is linked to poor outcomes and the association seems to be stronger for patients without diabetes than for those with pre-existing diabetes. However, studies were not prospectively designed to compare patients with stress hyperglycaemia and preexisting diabetes, creating some limitations. Despite data from interventional studies ${ }^{1,2}$ and controlling for severity of illness, residual confounding could be difficult to completely eliminate. For example, patients with pre-existing diabetes might be more likely to undergo glycaemic monitoring and receive insulin treatment ${ }^{25}$ or other life-saving drugs ${ }^{58}$ in the hospital than would undiagnosed patients. Additionally, studies lack a consistent or strict definition of stress hyperglycaemia. ${ }^{47,51}$

Many studies do not have sufficient comparator groups because they are observational. For example, direct comparisons of glycaemic control in non-diabetic patients who have stress hyperglycaemia with diabetic patients are often unable to account for the change in glucose from baseline in the latter. Non-diabetic patients with stress hyperglycaemia should ideally be compared with those who have been diagnosed and who have deterioration of pre-illness glycaemic control to enable assessment of whether outcomes differ. However, results of a few studies ${ }^{27,40,49}$ show poor outcomes that persist in patients with newly discovered hyperglycaemia, after accounting for glycaemic control. Despite these limitations, results of controlled studies seem to show that treatment of hyperglycaemia in patients improves outcomes, although new data indicate that the quest for strict normoglycaemia is harmful. 


\section{Pathophysiology}

In the hospital setting, a combination of factors affect the development of stress hyperglycaemia (figure 2). The mechanisms for this disorder probably vary with the patients' underlying glucose tolerance, type and severity of disease, and stage of illness. The cause of hyperglycaemia in type 2 diabetes is a combination of insulin resistance and $\beta$-cell secretory defects. However, the development of stress hyperglycaemia is caused by a highly complex interplay of counter-regulatory hormones such as catecholamines, growth hormone, cortisol, and cytokines (figure 3). ${ }^{34,59,60}$ The underlying illness might affect the scale of cytokine production and hormonal derangements. Complex feedforward and feedback mechanisms between hormones and cytokines exist, ${ }^{61}$ and this neurohormonal environment ultimately leads to excessive hepatic glucose production and insulin resistance. ${ }^{59,60} \mathrm{High}$ hepatic output of glucose, especially through gluconeogenesis, seems to be the most important contributor to stress hyperglycaemia. ${ }^{62,63}$ Excessive glucagon is the primary mediator of gluconeogenesis, ${ }^{64}$ although epinephrine ${ }^{65}$ and cortisol ${ }^{66}$ also contribute. Tumour necrosis factor- $\alpha(\mathrm{TNF} \alpha)$ might promote gluconeogenesis by stimulating glucagon production. ${ }^{67}$

Insulin resistance during illness is characterised by an inability to suppress central hepatic glucose production. In the periphery, insulin resistance is mediated through two major pathways. Reduced insulin-mediated glucose uptake results from defects in postreceptor insulin signalling ${ }^{68}$ and downregulation of glucose transporter (GLUT)-4. ${ }^{69}$ Additionally, impaired non-oxidative glucose disposal probably results from reduced skeletal muscle glycogen synthesis. ${ }^{70}$ Both excess cortisol ${ }^{71}$ and epinephrine ${ }^{72}$ reduce insulin-mediated glucose uptake. Cytokines such as TNF $\alpha{ }^{73}$ and interleukin $1^{74}$ inhibit postreceptor insulin signalling. Severity of illness is associated with a proportional rise in serum cytokines ${ }^{25}$ and insulin resistance. ${ }^{75}$ Furthermore, hyperglycaemia exacerbates the cytokine, inflammatory, and oxidative stress response, potentially setting up a vicious cycle whereby hyperglycaemia leads to further hyperglycaemia. ${ }^{76-78}$ Resolution of hyperglycaemia is associated with normalisation of the inflammatory response. ${ }^{78}$

Insulin resistance ultimately promotes a catabolic state in which lipolysis takes place. Excessive circulating free fatty acids in turn exacerbate insulin resistance by disrupting endorgan insulin signalling ${ }^{79}$ and glycogen synthase. ${ }^{80}$ This lipotoxicity aggravates the inflammatory state, paralleling the effects of glucotoxicity. ${ }^{81}$ Glucotoxicity, lipotoxicity, and inflammation are key components of what might be viewed as an exaggerated global insulin-resistance syndrome associated with acute illness. These components also promote endothelial dysfunction, which has a complex reciprocal cause-effect relation with insulin resistance. ${ }^{82}$ Hyperinsulinaemia might impart additive consequences to that of hyperglycaemia, including exaggerated inflammatory and counter-regulatory hormone responses and impaired fibrinolysis. ${ }^{83,84}$

Despite reduced insulin-mediated glucose uptake, an early increase in whole-body glucose uptake takes place-mainly as a result of cytokine-mediated up regulation of GLUT-1. ${ }^{85-88}$ GLUT-1 is a ubiquitous glucose transporter that is involved in non-insulin-mediated glucose uptake. Although non-oxidative metabolism (eg, glycogen synthesis) is impaired, oxidative glucose metabolism is upregulated early. ${ }^{89}$ In addition to patient-specific factors, certain therapeutic interventions such as catecholamine infusions, corticosteroids, and enteral and parenteral nutrition can worsen or precipitate hyperglycaemia. ${ }^{25}$ No studies of mechanisms comparing critically ill patients with diabetes or stress hyperglycaemia are available. Therefore, whether differences in pathophysiology explain differences in outcomes is unclear. 


\section{Mechanism of adverse outcomes}

The typical chronic complications of diabetes take several years to develop; therefore, the explanation for a rise in harm that is related to stress hyperglycaemia needs further consideration (figure 4). Stress hyperglycaemia is mediated by much greater inflammatory and neuroendocrine derangements than are expected in chronic hyperglycaemia associated with diabetes. Possibly, these derangements heighten susceptibility to benefits of interventions. For example, multiorgan failure is associated with widespread microvascular endothelial dysfunction, and improved outcomes associated with intensive insulin therapy have been attributed in part to endothelial protection. ${ }^{90}$

Some evidence suggests that chronic hyperglycaemia sets up a pattern of cellular conditioning that might actually be protective of acute hyperglycaemia-mediated damage during critical illness. One mechanism for this effect might be the preferential downregulation of glucose transporters under conditions of chronic rather than intermittent hyperglycaemia. GLUT-1 and GLUT-3 are facilitative glucose transporters that allow glucose to enter cells independently of insulin. Several factors that upregulate these transporters are elaborated during critical illness, potentially allowing glucose to enter cells unchecked by normal downregulatory responses. ${ }^{91}$ Thus, a wide range of tissues might be susceptible to enhanced glucose toxicity as a result of acute illness. ${ }^{91,92}$ Whether patients with chronic hyperglycaemia are able to compensate by downregulating glucose transporters is unknown. Various oxidative stressors prevent the downregulation of GLUT-1 transporters in vascular endothelial cells. ${ }^{93}$

Acute fluctuations in glucose concentrations are associated with mortality in acutely ill patients, independently of mean glucose concentration. ${ }^{94-97}$ Repetitive acute glucose fluctuations induce more endothelial apoptosis, ${ }^{98}$ and greater endothelial dysfunction and oxidative stress responses compared with the less variable excursions both in vitro ${ }^{98,99}$ and in patients with or without known diabetes. ${ }^{100,101}$ Furthermore, oxidative stress seems to have a unifying causal role in the stimulation of classic intracellular pathways that mediate chronic complications of hyperglycaemia. ${ }^{102}$ Therefore, increased oxidative stress during acute hyperglycaemia (by contrast with chronic hyperglycaemia or diabetes) would seem to be a plausible mechanism for additive adverse effects of stress hyperglycaemia.

Pre-existing microvascular and macrovascular disease in patients with diabetes might affect outcomes associated with strict glycaemic control. For example, patients with diabetic autonomic dysfunction might be predisposed to development of severe hypoglycaemia as a result of hypoglycaemia unawareness. Patients with cardiac autonomic dysfunction might be predisposed to development of arrythmias as a result of hypoglycaemia. Furthermore, the response to hypoglycaemia could be more severe in patients with previous evidence of diabetes who have pre-existing endothelial dysfunction and greater tendency for ischaemic events than in those without diabetes. ${ }^{103}$ Hypoglycaemia elicits a counter-regulatory hormonal response that might aggravate the inflammatory state already present in acute illness. Whether hypoglycaemia is an independent indicator of overall risk of death, or merely a marker of severity of illness is unclear. ${ }^{104,105}$ In patients with severe brain injury, changes in glucose transport might in part account for an association of tight glycaemic control with abnormal cerebral glucose metabolism and poor outcomes. ${ }^{106}$ Conversely, in the Leuven studies, ${ }^{21}$ a low propensity for hypoglycaemia does not by itself explain any susceptibility to benefits of glucoregulation.

\section{Management}

Current guidelines ${ }^{107,108}$ do not recognise stress hyperglycaemia as being different from pre-existing diabetes, although such guidelines might specify separate targets for ICU and 
non-ICU patients. Other than the distinction between surgical and medical ICU patients, insufficient data are available to recommend risk stratification for assignment of glucose targets with respect to the cause or severity of hyperglycaemia. However, some investigators have noted that the concept of separate targets is similar to other situations, in which rapid correction of longstanding physiology is detrimental. ${ }^{22}$ Guidelines are being revised in response to the NICE-SUGAR results. We emphasise that providers "should not abandon glucose management in the ICU setting, but that a less intensive target similar to that of the conventional treatment arm (mean glucose $8 \mathrm{mmol} / \mathrm{L}$ ) be implemented". ${ }^{109,110}$ Outside of the ICU, no inpatient data exist to guide treatment decisions, but individualised glucose targets based on outpatient recommendations are reasonable. ${ }^{107,108}$

No studies have specifically investigated the best method for the management of stress hyperglycaemia. Therefore, to follow general recommendations for hospital inpatients with hyperglycaemia is reasonable, keeping in mind that stress hyperglycaemia by definition is a transient, often dynamic disorder that responds to changes in disease course. Specific recommendations for implementation of glycaemic control generally include insulin therapy, and in the surgical and medical ICU insulin infusions are favoured. Stress hyper glycaemia lends itself ideally to insulin, which is rapidly titratable in response to changes in glucose concentrations. Intravenous insulin is highly effective and can be adjusted frequently. In patients with oedema or hypoperfusion, subcutaneous insulin might result in insulin stacking and hypoglycaemia. ${ }^{111}$ However, intravenous insulin is still relegated to the ICU in many institutions because of concerns about safety and about adequate staffing.

Subcutaneous insulin is reasonable for most general surgical and medical patients outside the ICU. In the outpatient setting, insulin analogues usually produce a lower incidence of hypoglycaemia than do regular human insulin or neutral protamine hagedom (NPH) insulin, but this finding was not confirmed in an inpatient study of patients with type 2 diabetes. ${ }^{112}$ Results of another randomised controlled trial ${ }^{113}$ of insulin naive patients with diabetes showed that subcutaneous basal bolus insulin was better than was sliding-scale insulin for attainment of safe, effective glycaemic control. Investigators were able to safely escalate the dose of insulin daily, but seemed to need up to 3 days to reach a target glucose of $7.8 \mathrm{mmol} /$ L. In another study ${ }^{114}$ patients who initially received intravenous insulin in the ICU and then were rapidly transitioned to subcutaneous insulin for transfer to the wards had good outcomes.

Carers should take steps to pre-emptively adjust therapy in response to changes in nutritional needs. This strategy could include consistent carbohydrate diets or giving prandial insulin according to estimated carbohydrate intake. During enteral feeding, anticipatory orders, including increased monitoring, withholding insulin, and, if needed, dextrose infusion in case of planned or unplanned interruption are necessary. The amount of exogenous, intravenous, and enteral glucose given is commonly overlooked, and can be restricted when necessary - eg, by changing enteral formulas. No prospective data show that interventions designed specifically to reduce glucose fluctuations improve outcomes. However, fluctuations in glucose might be kept to a minimum with physiological insulin replacement, ${ }^{115,116}$ especially to ensure adequate carbohydrate coverage. Insulin-drip protocols effectively provide basal and correction insulin coverage, but additional subcutaneous short-acting insulin is usually necessary to prevent rapid glucose swings in patients with intermittent exogenous carbohydrate exposure. ${ }^{117}$ Furthermore, proper training and use of improved algorithms for intravenous insulin could be useful. ${ }^{117-120}$

Anticipatory reduction in total daily insulin doses of at least 10-20\% are sometimes necessary in patients with tight glucose control who are clinically improving. Experts do not advocate the use of oral hypoglycaemic agents agents for most hospital inpatients because of 
the often slow onset and resolution of action, risk of hypoglycaemia in patients with unpredictable nutritional intake, and because of contraindications, such as frequent administration of contrast dye in patients taking metformin. ${ }^{104}$

\section{Prevention and monitoring}

In most patients, hospital-related hyperglycaemia is not generally predictable or preventable. However, early recognition and interception might prevent its persistence and exacerbation. In patients with diabetes, observational data suggest that long-term preadmission glycaemic control might affect the operative risk for both cardiovascular and non-cardiac complications. ${ }^{55,121}$ Furthermore, preoperative glucotoxicity could affect the ease with which postoperative control is achieved. Although gross intraoperative hyperglycaemia might be deleterious for certain procedures, intraoperative use of strict glycaemic control is still controversial. ${ }^{56,57}$

The effectiveness and safety of any glycaemic intervention depends upon the ability to accurately monitor glucose. Especially in the ICU, many confounding factors in glucose measurement such as anaemia or hypotension might be present simultaneously, and could render typical bedside capillary point of care devices inaccurate. ${ }^{122}$ Because of their increased severity of illness, glucose measurement in patients with stress hyperglycaemia can be especially challenging. Real-time continuous glucose monitoring with interstitial glucose measurements could potentially reduce the frequency of blood glucose sampling, but this method is even more vulnerable to error and is only ap proved for adjunctive use. ${ }^{123}$ Finally, an oral-glucose-tolerance-test or close monitoring at follow-up are needed at discharge to identify patients with underlying diabetes and prevent subacute (eg, infectious) or long-term complications.

\section{Future direction and conclusion}

Prospective studies with follow-up data comparing diabetes and stress hyperglycaemia are needed. $\mathrm{HbA}_{1 \mathrm{c}}$ should be reported both to exclude undiagnosed probable diabetes and to infer whether patients with diabetes have stress-related exacerbation of hyperglycaemia. Patients with non-diabetic stress hyperglycaemia should be compared with a subgroup of patients with diabetes who have stress-related exacerbation of hyperglycaemia, and those with non-diabetic normoglycaemia should be compared with those with diabetes whose glucose control was unaltered at admission. Additionally, researchers examining risks and outcomes of hypoglycaemia should place special emphasis on high-risk cardiac subgroups. The optimum target glucose range in stress conditions is still undefined, and different targets should be compared on the basis of their risk-to-benefit ratios.

Until such data are available, efforts to improve ease of use and safety of intensive glycaemic control, such as computerised insulin dosing algorithms and glucose monitoring techniques, might mitigate the need for risk stratification. Stress hyperglycaemia is a heterogeneous entity with unique pathophysiological features. Present practice is to treat hyperglyacemia irrespective of its cause. However, we suggest that the chronicity of hyperglycaemia and other factors specific to patients or populations merits special consideration.

\section{References}

1. Van den Berghe G, Wouters P, Weekers F, et al. Intensive insulin therapy in the critically ill patients. N Engl J Med. 2001; 345:1359-67. [PubMed: 11794168]

2. Van den Berghe G, Wilmer A, Hermans G, et al. Intensive insulin therapy in the medical ICU. N Engl J Med. 2006; 354:449-61. [PubMed: 16452557] 
3. Brunkhorst FM, Engel C, Bloos F, et al. German Competence Network Sepsis (SepNet). Intensive insulin therapy and pentastarch resuscitation in severe sepsis. N Engl J Med. 2008; 358:125-39. [PubMed: 18184958]

4. Devos P, Preiser J, Melot C. Impact of tight glucose control by intensive insulin therapy on ICU mortality and the rate of hypoglycaemia: final results of the Glucontrol study. Intensive Care Med. 2007; 33 (suppl):189.

5. De La Rosa GD, Donado JH, Restrepo AH, et al. Grupo de Investigacion en Cuidado intensivo: GICIHPT. Strict glycaemic control in patients hospitalised in a mixed medical and surgical intensive care unit: a randomised clinical trial. Crit Care. 2008; 12:120. [PubMed: 18394177]

6. Arabi YM, Dabbagh OC, Tamim HM, et al. Intensive versus conventional insulin therapy: a randomized controlled trial in medical and surgical critically ill patients. Crit Care Med. 2008; 36:3190-97. [PubMed: 18936702]

7. Wiener RS, Wiener DC, Larson RJ. Benefits and risks of tight glucose control in critically ill adults: a meta-analysis. JAMA. 2008; 300:933-44. [PubMed: 18728267]

8. Finfer S, Chittock DR, Su SY, et al. NICE-SUGAR Study Investigators. Intensive versus conventional glucose control in critically ill patients. N Engl J Med. 2009; 360:1283-97. [PubMed: 19318384]

9. Kitabchi AE, Freire AX, Umpierrez GE. Evidence for strict inpatient blood glucose control: time to revise glycemic goals in hospitalized patients. Metabolism. 2008; 57:116-20. [PubMed: 18078868]

10. Clement S, Braithwaite SS, Magee MF, et al. Management of diabetes and hyperglycemia in hospitals. Diabetes Care. 2004; 27:553-91. [PubMed: 14747243]

11. Centers for Disease Control and Prevention. National diabetes fact sheet: general information and national estimates on diabetes in the United States, 2005. Atlanta, GA: Department of Health and Human Services, Centers for Disease Control and Prevention; 2005.

12. Wallander M, Malmberg K, Ryden L, Tenerz A. Oral glucose tolerance test: a reliable tool for early detection of glucose abnormalities in patients with acute myocardial infarction in clinical practice. Diabetes Care. 2008; 31:36-38. [PubMed: 17909086]

13. Ishihara M, Inoue I, Kawagoe T, et al. Is admission hyperglycaemia in non-diabetic patients with acute myocardial infarction a surrogate for previously undiagnosed abnormal glucose tolerance? Eur Heart J. 2006; 27:2413-19. [PubMed: 17000629]

14. Hashimoto K, Ikewaki K, Yagi H, et al. Glucose intolerance is common in Japanese patients with acute coronary syndrome who were not previously diagnosed with diabetes. Diabetes Care. 2005; 28:1182-86. [PubMed: 15855586]

15. Bartnik M, Rydén L, Ferrari R, et al. Euro Heart Survey Investigators . The prevalence of abnormal glucose regulation in patients with coronary artery disease across Europe: the Euro Heart Survey on diabetes and the heart. Eur Heart J. 2004; 25:1880-90. [PubMed: 15522466]

16. Gray CS, Scott JF, French JM, Alberti KG, O'Connell JE. Prevalence and prediction of unrecognised diabetes mellitus and impaired glucose tolerance following acute stroke. Age Ageing. 2004; 33:71-77. [PubMed: 14695867]

17. Vancheri F, Curcio M, Burgio A, et al. Impaired glucose metabolism in patients with acute stroke and no previous diagnosis of diabetes mellitus. QJM. 2005; 98:871-78. [PubMed: 16239309]

18. Greci LS, Kailasam M, Malkani S, et al. Utility of $\mathrm{HbA}(1 \mathrm{c})$ levels for diabetes case finding in hospitalized patients with hyperglycemia. Diabetes Care. 2003; 26:1064-68. [PubMed: 12663574]

19. Wexler DJ, Nathan DM, Grant RW, Regan S, Van Leuvan AL, Cagliero E. Prevalence of elevated hemoglobin A1c among patients admitted to the hospital without a diagnosis of diabetes. J Clin Endocrinol Metab. 2008; 93:4238-44. [PubMed: 18697862]

20. Furnary AP, Wu Y. Clinical effects of hyperglycemia in the cardiac surgery population: the Portland diabetic project. Endocr Pract. 2006; 12 (suppl):22-26. [PubMed: 16905513]

21. Umpierrez GE, Isaacs SD, Bazargan N, You X, Thaler LM, Kitabchi AE. Hyperglycemia: An independent marker of in-hospital mortality in patients with undiagnosed diabetes. J Clin Endocrinol Metab. 2002; 87:978-82. [PubMed: 11889147]

22. Van den Berghe G, Wilmer A, Milants I, et al. Intensive insulin therapy in mixed medical/surgical intensive care units: benefit versus harm. Diabetes. 2006; 55:3151-59. [PubMed: 17065355] 
23. Egi M, Bellomo R, Stachowski E, et al. Blood glucose concentration and outcome of critical illness: the impact of diabetes. Crit Care Med. 2008; 36:2249-55. [PubMed: 18664780]

24. Rady MY, Johnson DJ, Patel BM, Larson JS, Helmers RA. Influence of individual characteristics on outcome of glycemic control in intensive care unit patients with or without diabetes mellitus. Mayo Clin Proc. 2005; 80:1558-67. [PubMed: 16342648]

25. Whitcomb BA, Pradhan EK, Pittas AG, Roghmann MC, Perencevich EN. Impact of admission hyperglycemia on hospital mortality in various intensive care unit populations. Crit Care Med. $2005 ; 33: 2272-77$.

26. Leonidou L, Mouzaki A, Michalaki M, et al. Cytokine production and hospital mortality in patients with sepsis-induced stress hyperglycemia. J Infection. 2007; 55:340-46.

27. Cao JJ, Hudson M, Jankowski M, Whitehouse F, Weaver WD. Relation of chronic and acute glycemic control on mortality in acute myocardial infarction with diabetes mellitus. Am J Cardiol. 2005; 96:183-86. [PubMed: 16018838]

28. Aronson D, Hammerman H, Kapeliovich MR, et al. Fasting glucose in acute myocardial infarction: incremental value for long-term mortality and relationship with left ventricular systolic function. Diabetes Care. 2007; 30:960-66. [PubMed: 17392556]

29. Worthley MI, Shrive FM, Anderson TJ, Traboulsi M. Prognostic implication of hyperglycemia in myocardial infarction and primary angioplasty. Am J Med. 2007; 120(643):e1-7. [PubMed: 17602940]

30. Nordin C, Amiruddin R, Rucker L, Choi J, Kohli A, Marantz PR. Diabetes and stress hyperglycemia associated with myocardial infarctions at an urban municipal hospital: prevalence and effect on mortality. Cardiol Rev. 2005; 13:223-30. [PubMed: 16106183]

31. Farrokhnia N, Björk E, Lindbäck J, Terent A. Blood glucose in acute stroke, different therapeutic targets for diabetic and non-diabetic patients? Acta Neurol Scand. 2005; 112:81-87. [PubMed: 16008532]

32. Fogelholm R, Murros K, Rissanen A, Avikainen S. Admission blood glucose and short term survival in primary intracerebral haemorrhage: a population based study. J Neurol Neurosurg Psychiatry. 2005; 76:349-53. [PubMed: 15716524]

33. Petursson P, Herlitz J, Caidahl K, et al. Admission glycaemia and outcome after acute coronary syndrome. Int J Cardiol. 2007; 116:315-20. [PubMed: 16854479]

34. Ishihara M, Kagawa E, Inoue I, et al. Impact of admission hyperglycemia and diabetes mellitus on short- and long-term mortality after acute myocardial infarction in the coronary intervention era. Am J Cardiol. 2007; 99:1674-79. [PubMed: 17560874]

35. Agwunobi AO, Reid C, Maycock P, Little RA, Carlson GL. Insulin resistance and substrate utilization in human endotoxemia. J Clin Encrinol Metab. 2000; 85:3770-78.

36. Ishihara M, Kojima S, Sakamoto T, et al. Japanese Acute Coronary Syndrome Study Investigators: Acute hyperglycemia is associated with adverse outcome after acute myocardial infarction in the coronary intervention era. Am Heart J. 2005; 150:814-20. [PubMed: 16209987]

37. Stranders I, Diamant M, van Gelder RE, et al. Admission blood glucose level as risk indicator of death after myocardial infarction in patients with and without diabetes mellitus. Arch Intern Med. 2004; 164:982-88. [PubMed: 15136307]

38. Schiele F, Descotes-Genon V, Seronde MF, et al. Investigators of the Réseau Franc Comtois de Cardiologie. Predictive value of admission hyperglycaemia on mortality in patients with acute myocardial infarction. Diabet Med. 2006; 23:1370-76. [PubMed: 17116190]

39. Müdespacher D, Radovanovic D, Camenzind E, et al. Admission glycaemia and outcome in patients with acute coronary syndrome. Diab Vasc Dis Res. 2007; 4:346-52. [PubMed: 18158706]

40. Meier JJ, Deifuss S, Klamann A, Launhardt V, Schmiegel WH, Nauck MA. Plasma glucose at hospital admission and previous metabolic control determine myocardial infarct size and survival in patients with and without type 2 diabetes: the Langendreer Myocardial Infarction and Blood Glucose in Diabetic Patients Assessment (LAMBDA). Diabetes Care. 2005; 28:2551-53. [PubMed: 16186299]

41. Szczudlik A, Slowik A, Turaj W, et al. Transient hyperglycemia in ischemic stroke patients. J Neurol Sci. 2001; 189:105-11. [PubMed: 11535240] 
42. Krinsley JS. Glycemic control, diabetic status, and mortality in a heterogeneous population of critically ill patients before and during the era of intensive glycemic management: six and one-half years experience at a university-affiliated community hospital. Semin Thorac Cardiovasc Surg. 2006; 18:317-25. [PubMed: 17395028]

43. Freire AX, Bridges L, Umpierrez GE, Kuhl D, Kitabchi AE. Admission hyperglycemia and other risk factors as predictors of hospital mortality in a medical ICU population. Chest. 2005; 128:3109-16. [PubMed: 16304250]

44. Ainla T, Baburin A, Teesalu R, Rahu M. The association between hyperglycaemia on admission and 180-day mortality in acute myocardial infarction patients with and without diabetes. Diabet Med. 2005; 22:1321-25. [PubMed: 16176190]

45. Kes VB, Solter VV, Supanc V, Demarin V. Impact of hyperglycemia on ischemic stroke mortality in diabetic and non-diabetic patients. Ann Saudi Med. 2007; 27:352-55. [PubMed: 17921684]

46. Van den Berghe G, Wouters PJ, Bouillon R, et al. Outcome benefit of intensive insulin therapy in the critically ill: Insulin dose versus glycemic control. Crit Care Med. 2003; 31:359-66. [PubMed: 12576937]

47. Capes SE, Hunt D, Malmberg K, Gerstein HC. Stress hyperglycaemia and increased risk of death after myocardial infarction in patients with and without diabetes: a systematic overview. Lancet. 2000; 355:773-78. [PubMed: 10711923]

48. Kosiborod M, Rathore SS, Inzucchi SE, et al. Admission glucose and mortality in elderly patients hospitalized with acute myocardial infarction: implications for patients with and without recognized diabetes. Circulation. 2005; 111:3078-86. [PubMed: 15939812]

49. Hadjadj S, Coisne D, Mauco G, et al. Prognostic value of admission plasma glucose and HbA1c in acute myocardial infarction. Diabetic Med. 2004; 21:305-10. [PubMed: 15049930]

50. Vibo R, Kõrv J, Roose M. One-year outcome after first-ever stroke according to stroke subtype, severity, risk factors and pre-stroke treatment: a population-based study from Tartu, Estonia. Eur J Neurol. 2007; 14:435-39. [PubMed: 17388994]

51. Capes SE, Hunt D, Malmberg K, Pathak P, Gerstein HC. Stress hyperglycemia and prognosis of stroke in nondiabetic and diabetic patients: a systematic overview. Stroke. 2001; 32:2426-32. [PubMed: 11588337]

52. Stöllberger C, Exner I, Finsterer J, Slany J, Steger C. Stroke in diabetic and non-diabetic patients: course and prognostic value of admission serum glucose. Ann Med. 2005; 37:357-64. [PubMed: 16179271]

53. Furnary AP, Wu Y. Eliminating the diabetic disadvantage: the Portland Diabetic Project. Semin Thorac Cardiovasc Surg. 2006; 18:302-08. [PubMed: 17395026]

54. Jones KW, Cain AS, Mitchell JH, et al. Hyperglycemia predicts mortality after CABG: postoperative hyperglycemia predicts dramatic increases in mortality after coronary artery bypass graft surgery. J Diabetes Complications. 2008; 22:365-70. [PubMed: 18413193]

55. Dronge AS, Perkal MF, Kancir S, Concato J, Aslan M, Rosenthal RA. Long-term glycemic control and postoperative infectious complications. Arch Surg. 2006; 141:375-80. [PubMed: 16618895]

56. Pasternak JJ, McGregor DG, Schroeder DR, et al. for the IHAST Investigators. Hyperglycemia in patients undergoing cerebral aneurysm surgery: its association with long-term gross neurologic and neuropsychological function. Mayo Clin Proc. 2008; 83:406-17. [PubMed: 18380986]

57. Gandhi GY, Murad MH, Flynn DN, et al. Effect of perioperative insulin infusion on surgical morbidity and mortality: systematic review and meta-analysis of randomized trials. Mayo Clin Proc. 2008; 83:418-30. [PubMed: 18380987]

58. Kosuge M, Kimura K, Kojima S, et al. for the; Japanese Acute Coronary Syndrome Study (JACSS) Investigators . Effects of glucose abnormalities on in-hospital outcome after coronary intervention for acute myocardial infarction. Circ J. 2005; 69:375-79. [PubMed: 15791028]

59. Barth E, Albuszies G, Baumgart K, et al. Glucose metabolism and catecholamines. Crit Care Med. 2007; 35 (suppl):508-18.

60. Andrewq RC, Walker BR. Glucocorticoids and insulin resistance: old hormones, new targets. Clin Sci. 1999; 96:513-23. [PubMed: 10209084]

61. Chrousos GP. The hypothalamic-pituitary-adrenal axis and immune-mediated inflammation. N Engl J Med. 1995; 332:1351-62. [PubMed: 7715646] 
62. Jeevanandam M, Young DH, Schiller WR. Glucose turnover, oxidation, and indices of recycling in severely traumatized patients. J Trauma. 1990; 30:582-89. [PubMed: 2342143]

63. McGuinness OP, Fugiwara T, Murrell S, et al. Impact of chronic stress hormone infusion on hepatic carbohydrate metabolism in the conscious dog. Am J Physiol. 1993; 265:314-22.

64. Lang CH, Bagby GJ, Blakesley HL, Spitzer JJ. Importance of hyperglucagonemia in eliciting the sepsis-induced increase in glucose production. Circ Shock. 1989; 29:181-91. [PubMed: 2574079]

65. McGuinness OP, Shau V, Benson EM, et al. Role of epinephrine and norepinephrine in the metabolic response to stress hormone infusion in the conscious dog. Am J Physiol. 1997; 273:67481.

66. Fujiwara T, Cherrington AD, Neal DN, McGuinness OP. Role of cortisol in the metabolic response to stress hormone infusion in the conscious dog. Metabolism. 1996; 45:571-78. [PubMed: 8622599]

67. Blumberg D, Hochwald S, Burt M, Donner D, Brennan MF. Tumor necrosis factor alpha stimulates gluconeogenesis from alanine in vivo. J Surg Oncol. 1995; 59:220-24. [PubMed: 7630167]

68. Fan J, Li YH, Wojnar MM, Lang CH. Endotoxin-induced alterations in insulin-stimulated phosphorylation of insulin receptor, IRS-1, and MAP kinase in skeletal muscle. Shock. 1996; 6:164-70. [PubMed: 8885080]

69. Lang CH, Dobrescu C, Mészáros K. Insulin-mediated glucose uptake by individual tissues during sepsis. Metabolism. 1990; 39:1096-107. [PubMed: 2215256]

70. Green CJ, Campbell IT, O'Sullivan E, et al. Septic patients in multiple organ failure can oxidize infused glucose, but non-oxidative disposal (storage) is impaired. Clin Sci (London). 1995; 89:601-09. [PubMed: 8549078]

71. Dimitriadis G, Leighton B, Parry-Billings M, et al. Effects of glucocorticoid excess on the sensitivity of glucose transport and metabolism to insulin in rat skeletal muscle. Biochem J. 1997; 321:707-12. [PubMed: 9032457]

72. Lang CH. Sepsis-induced insulin resistance in rats is mediated by a beta-adrenergic mechanism. Am J Physiol. 1992; 263:703-11.

73. Ishizuka K, Usui I, Kanatani Y, et al. Chronic tumor necrosis factor-alpha treatment causes insulin resistance via insulin receptor substrate-1 serine phosphorylation and suppressor of cytokine signaling-3 induction in 3T3-L1 adipocytes. Endocrinology. 2007; 148:2994-3003. [PubMed: 17379643]

74. He J, Usui I, Ishizuka K, et al. Interleukin-1alpha inhibits insulin signaling with phosphorylating insulin receptor substrate-1 on serine residues in 3T3-L1 adipocytes. Mol Endocrinol. 2006; 20:114-24. [PubMed: 16150868]

75. Zauner A, Nimmerrichter P, Anderwald C, et al. Severity of insulin resistance in critically ill medical patients. Metabolism. 2007; 56:1-5. [PubMed: 17161218]

76. Ling P, Smith R, Bistrian B. Hyperglycemia enhances the cytokine production and oxidative responses to a low but not high dose of endotoxin in rats. Crit Care Med. 2005; 33:1084-89. [PubMed: 15891340]

77. Yu WK, Li WQ, Li N, Li JS. Influence of acute hyperglycemia in human sepsis on inflammatory cytokine and counterregulatory hormone concentrations. World J Gastroenterol. 2003; 9:1824-27. [PubMed: 12918129]

78. Stentz FB, Umpierrez GE, Cuervo R, Kitabchi AE. Proinflammatory cytokines, markers of cardiovascular risks, oxidative stress, and lipid peroxidation in patients with hyperglycemic crises. Diabetes. 2004; 53:2079-86. [PubMed: 15277389]

79. Dresner A, Laurent D, Marcucci M, et al. Effects of free fatty acids on glucose transport and IRS-1-associated phosphatidylinositol 3-kinase activity. J Clin Invest. 1999; 103:253-59. [PubMed: 9916137]

80. Kelley DE, Mokan M, Simoneau JA, Mandarino LJ. Interaction between glucose and free fatty acid metabolism in human skeletal muscle. J Clin Invest. 1993; 92:91-98. [PubMed: 8326021]

81. Krogh-Madsen R, Plomgaard P, Akerstrom T, Møller K, Schmitz O, Pedersen BK. Effect of shortterm intralipid infusion on the immune response during low-dose endotoxemia in humans. Am $\mathrm{J}$ Physiol Endocrinol Metab. 2008; 294:371-79. 
82. Kim JA, Montagnani M, Koh KK, Quon MJ. Reciprocal relationships between insulin resistance and endothelial dysfunction: molecular and pathophysiological mechanisms. Circulation. 2006; 113:1888-904. [PubMed: 16618833]

83. Stegenga ME, van der Crabben SN, Blümer RM, et al. Hyperglycemia enhances coagulation and reduces neutrophil degranulation, whereas hyperinsulinemia inhibits fibrinolysis during human endotoxemia. Blood. 2008; 112:82-89. [PubMed: 18316629]

84. Soop M, Duxbury H, Agwunobi AO, et al. Euglycemic hyperinsulinemia augments the cytokine and endocrine responses to endotoxin in humans. Am J Physiol Endocrinol Metab. 2002; 282:1276-85.

85. Lang CH, Dobrescu C. Gram-negative infection increases noninsulin-mediated glucose disposal. Endocrinology. 1991; 128:645-53. [PubMed: 1989854]

86. Gamelli RL, Liu H, He LK, Hofmann CA. Augmentations of glucose uptake and glucose transporter-1 in macrophages following thermal injury and sepsis in mice. J Leukoc Biol. 1996; 59:639-47. [PubMed: 8656048]

87. Zeller WP, The SM, Sweet M, et al. Altered glucose transporter mRNA abundance in a rat model of endotoxic shock. Biochem Biophys Res Commun. 1991; 176:535-40. [PubMed: 2018543]

88. Gamelli RL, Liu H, He LK, Hofmann CA. Alterations of glucose transporter mRNA and protein levels in brain following thermal injury and sepsis in mice. Shock. 1994; 1:395-400. [PubMed: 7735967]

89. Shangraw RE, Jahoor F, Wolfe RR, Lang CH. Pyruvate dehydrogenase inactivity is not responsible for sepsis-induced insulin resistance. Crit Care Med. 1996; 24:566-74. [PubMed: 8612405]

90. Langouche L, Vanhorebeek I, Vlasselaers D, et al. Intensive insulin therapy protects the endothelium of critically ill patients. J Clin Invest. 2005; 115:2277-86. [PubMed: 16075063]

91. Vanhorebeek I, Van den Berghe G. Diabetes of injury: novel insights. Endocrinol Metab Clin North Am. 2006; 35:859-72. [PubMed: 17127151]

92. Schetz M, Vanhorebeek I, Wouters PJ, Wilmer A, Van den Berghe G. Tight blood glucose control is renoprotective in critically ill patients. J Am Soc Nephrol. 2008; 19:571-8. [PubMed: 18235100]

93. Cohen G, Riahi Y, Alpert E, Gruzman A, Sasson S. The roles of hyperglycaemia and oxidative stress in the rise and collapse of the natural protective mechanism against vascular endothelial cell dysfunction in diabetes. Arch Physiol Biochem. 2007; 113:259-67. [PubMed: 18158647]

94. Egi M, Bellomo R, Stachowski E, French CJ, Hart G. Variability of blood glucose concentration and short-term mortality in critically ill patients. Anesthesiology. 2006; 105:244-52. [PubMed: 16871057]

95. Ali NA, O'Brien JM, Dungan K, et al. Glucose variability and mortality in patients with sepsis. Crit Care Med. 2008; 36:2316-21. [PubMed: 18596625]

96. Dossett LA, Cao H, Mowery NT, Dortch MJ, Morris JM Jr, May AK. Blood glucose variability is associated with mortality in the surgical intensive care unit. Am Surg. 2008; 74:679-85. [PubMed: 18705566]

97. Waeschle RM, Moerer O, Hilgers R, Herrmann P, Neumann P, Quintel M. The impact of the severity of sepsis on the risk of hypoglycaemia and glycaemic variability. Crit Care. 2008; 12:R129. [PubMed: 18939991]

98. Quagliaro L, Piconi L, Assaloni R, Martinelli L, Motz E, Ceriello A. Intermittent high glucose enhances apoptosis related to oxidative stress in human umbilical vein endothelial cells: the role of protein kinase C and NAD(P)H-oxidase activation. Diabetes. 2003; 52:2795-804. [PubMed: 14578299]

99. Quagliaro L, Piconi L, Assaloni R, et al. Intermittent high glucose enhances ICAM-1, VCAM-1 and E-selectin expression in human umbilical vein endothelial cells in culture: the distinct role of protein kinase $C$ and mitochondrial superoxide production. Atherosclerosis. 2005; 183:259-67. [PubMed: 16285992]

100. Monnier L, Mas E, Ginet C. Activation of oxidative stress by acute glucose fluctuations compared with sustained chronic hyperglycemia in patients with type 2 diabetes. JAMA. 2006; 295:1681-87. [PubMed: 16609090] 
101. Ceriello A, Esposito K, Piconi L, et al. Oscillating glucose is more deleterious to endothelial function and oxidative stress than mean glucose in normal and type 2 diabetic patients. Diabetes. 2008; 57:1349-54. [PubMed: 18299315]

102. Evans JL, Goldfine ID, Maddux BA, Grodsky GM. Oxidative stress and stress-activated signaling pathways: a unifying hypothesis of type 2 diabetes. Endocr Rev. 2002; 23:599-622. [PubMed: 12372842]

103. Wright RJ, Frier BM. Vascular disease and diabetes: is hypoglycaemia an aggravating factor? Diabetes Metab Res Rev. 2008; 24:353-63. [PubMed: 18461635]

104. Krinsley JS, Grover A. Severe hypoglycemia in critically ill patients: risk factors and outcomes. Crit Care Med. 2007; 35:2262-67. [PubMed: 17717490]

105. Vriesendorp TM, van Santen S, DeVries JH, et al. Predisposing factors for hypoglycemia in the intensive care unit. Crit Care Med. 2006; 34:96-101. [PubMed: 16374162]

106. Oddo M, Schmidt M, Carrera E, et al. Impact of tight glycemic control on cerebral glucose metabolism after severe brain injury: a microdialysis study. Crit Care Med. 2008; 36:3233-38. [PubMed: 18936695]

107. AACE Diabetes Mellitus Clinical Practice Guidelines Task Force. American Association of Clinical Endocrinologists medical guidelines for clinical practice for the management of diabetes mellitus. Endocr Pract. 2007; 13 (suppl):1-68. [PubMed: 17613449]

108. American Diabetes Association. Standards of medical care in diabetes-2009. Diabetes Care. 2009; 32 (suppl 1):13-61.

109. American Diabetes Association. [accessed May 1, 2009] Joint statement from ADA and AACE on the NICE-SUGAR study on intensive versus conventional glucose control in critically ill patients. http://www.diabetes.org/for-media/pr-NICE_SUGAR-study.jsp

110. The Endocrine Society. [accessed May 1, 2009] Endocrine Society statement to providers on NICE-SUGAR. http://www.endo-society.org/advocacy/legislative/SocietyStatementtoProvidersonNICESUGAR.cfm\#

111. Ariza-Andraca CR, Altamirano-Bustamante E, Frati-Munari AC, Altamirano-Bustamante P, Graef-Sanchez A. Delayed insulin absorption due to subcutaneous edema. Arch Invest Med. 1991; 22:229-33.

112. Umpierrez GE, Hor T, Smiley D, et al. Comparison of inpatient insulin regimens with detemir plus aspart versus neutral protamine hagedorn plus regular in medical Patients with Type 2 Diabetes. J Clin Endocrinol Metab. 2009; 94:564-69. [PubMed: 19017758]

113. Umpierrez GE, Smiley D, Zisman A, et al. Randomized study of basal-bolus insulin therapy in the inpatient management of patients with type 2 diabetes (RABBIT 2 Trial). Diabetes Care. 2007; 30:2181-86. [PubMed: 17513708]

114. Schmeltz LR, DeSantis AJ, Thiyagarajan V, et al. Reduction of surgical mortality and morbidity in diabetic patients undergoing cardiac surgery with a combined intravenous and subcutaneous insulin glucose management strategy. Diabetes Care. 2007; 30:823-28. [PubMed: 17229943]

115. Kudva YC, Basu A, Jenkins GD, et al. Glycemic variation and hypoglycemia in patients with well-controlled type 1 diabetes on a multiple daily insulin injection program with use of glargine and ultralente as basal insulin. Endocr Pract. 2007; 13:244-50. [PubMed: 17599855]

116. Saudek CD, Duckworth WC, Giobbie-Hurder A, et al. for the Department of Veterans A3 airs Implantable Insulin Pump Study Group . Implantable insulin pump vs multiple-dose insulin for non-insulin-dependent diabetes mellitus: a randomized clinical trial. JAMA. 1996; 276:1322-27. [PubMed: 8861991]

117. Davidson PC, Steed RD, Bode BW. Glucommander: a computer-directed intravenous insulin system shown to be safe, simple, and effective in $120618 \mathrm{~h}$ of operation. Diabetes Care. 2005; 28:2418-23. [PubMed: 16186273]

118. Reed CC, Stewart RM, Sherman M, et al. Intensive insulin protocol improves glucose control and is associated with a reduction in intensive care unit mortality. J Am Coll Surg. 2007; 204:104854. [PubMed: 17481538] 
119. Kanji S, Singh A, Tierney M, Meggison H, McIntyre L, Hebert PC. Standardization of intravenous insulin therapy improves the efficiency and safety of blood glucose control in critically ill adults. Intensive Care Med. 2004; 30:804-10. [PubMed: 15127193]

120. Vogelzang M, Loef BG, Regtien JG, et al. Computer-assisted glucose control in critically ill patients. Intensive Care Med. 2008; 34:1421-27. [PubMed: 18389221]

121. Noordzij PG, Boersma E, Schreiner F, et al. Increased preoperative glucose levels are associated with perioperative mortality in patients undergoing noncardiac, nonvascular surgery. Eur $\mathbf{J}$ Endocrinol. 2007; 156:137-42. [PubMed: 17218737]

122. Dungan K, Chapman J, Braithwaite SS, Buse J. Glucose measurement: confounding issues in setting targets for inpatient management. Diabetes Care. 2007; 30:403-09. [PubMed: 17259520]

123. Price GC, Stevenson K, Walsh TS. Evaluation of a continuous glucose monitor in an unselected general intensive care population. Crit Care Resusc. 2008; 10:209-16. [PubMed: 18798719] 
Search strategy and selection criteria

We searched PubMed with the terms "stress hyperglycemia", "diabetes",

"hyperglycemia" in conjunction with the key modifying terms "admission", "hospital", "inpatient", "intensive care unit", "critical care", "acute myocardial infarction", and "acute stroke". We also searched the reference lists of reports identified with this strategy for relevant publications. We prioritised controlled trials or meta-analyses and observational studies from the past 5 years. We used only studies in peer-reviewed journals, focusing on comparisons between stress hyperglycaemia and diabetes. 
Panel: Classification of hyperglycaemia in hospital ${ }^{9}$

Known diabetes

Diabetes diagnosed and treated before admission

Newly diagnosed diabetes

Fasting glucose more than $6.9 \mathrm{mmol} / \mathrm{L}$ or random glucose higher than $11.1 \mathrm{mmol} / \mathrm{L}$ during hospital stay and confirmed after discharge

\section{Hospital-related hyperglycaemia}

Fasting glucose more than $6.9 \mathrm{mmol} / \mathrm{L}$ or random glucose higher than $11.1 \mathrm{mmol} / \mathrm{L}$ during hospital stay that reverts to normal range after discharge

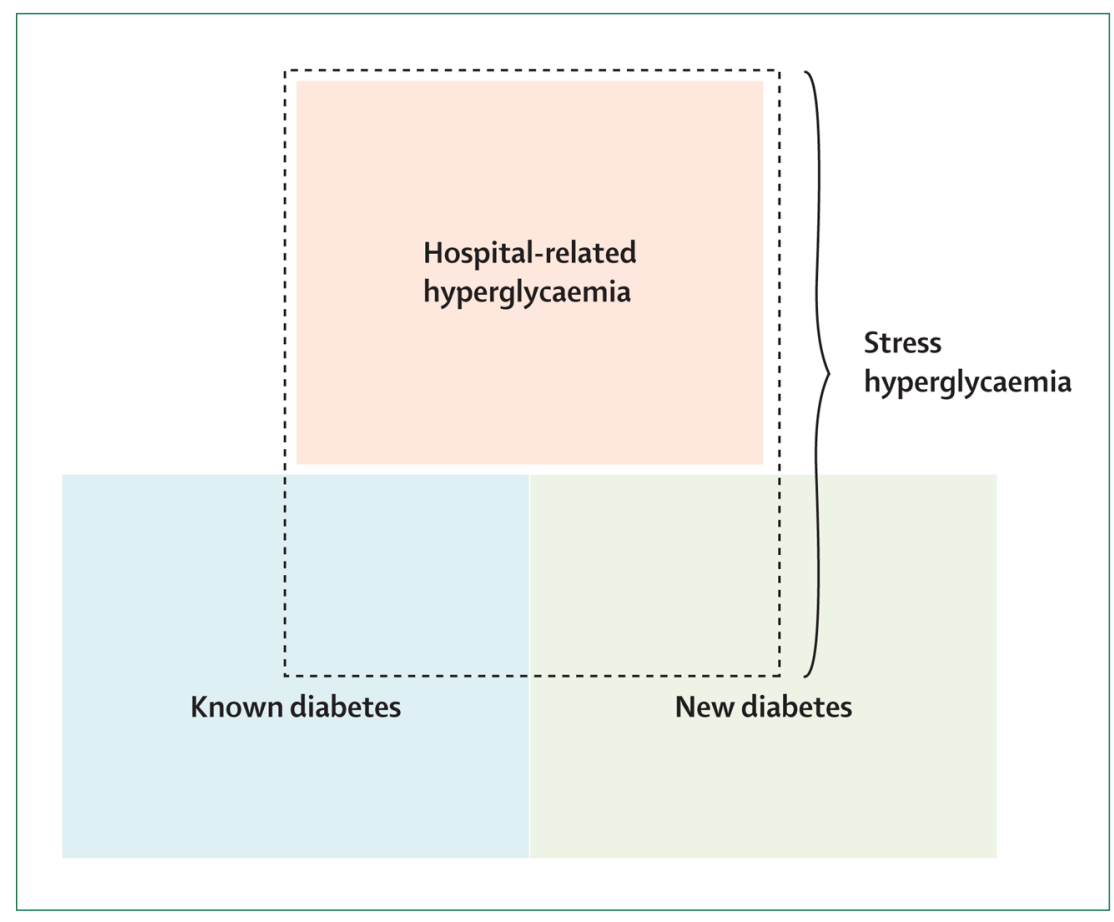

Figure 1.

Expanded view of stress hyperglycaemia 


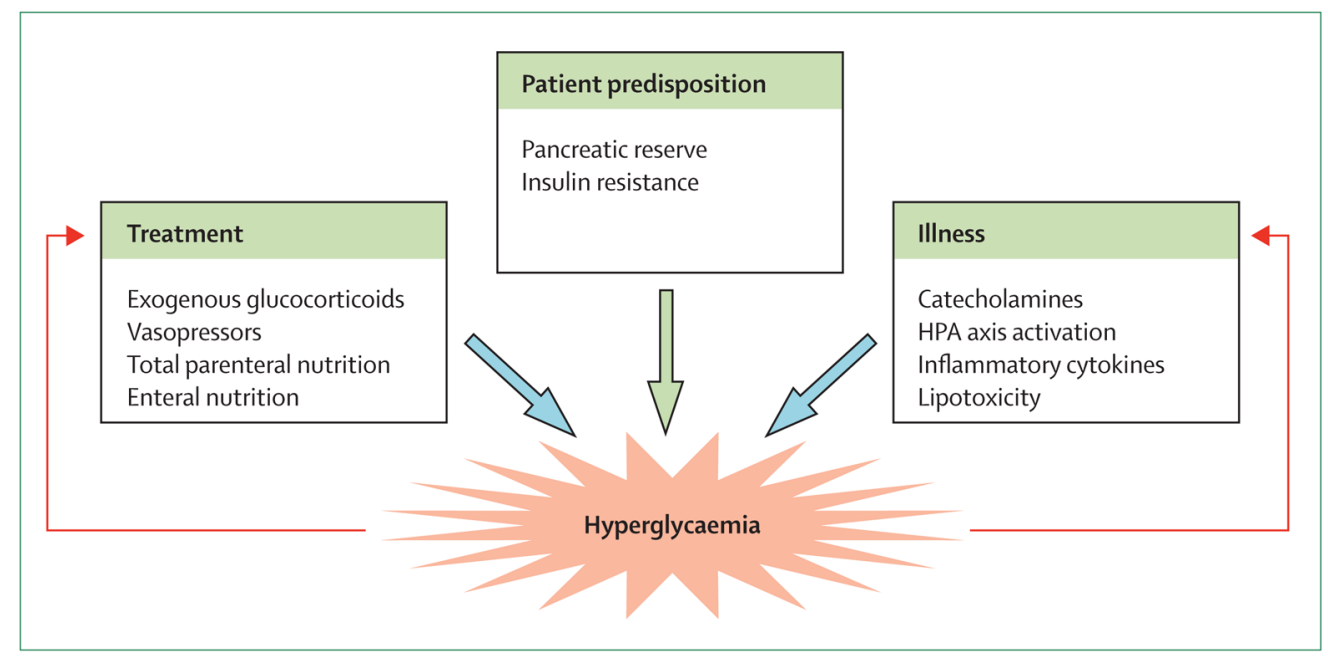

Figure 2. Multifactorial causes of hospital-related hyperglycaemia

Causal factors are specific to the patient, their illness, and their treatment. Hyperglycaemia can exacerbate some illness-specific factors and increase need for treatment-specific factors, leading to a vicious cycle by which hyperglycaemia causes further hyperglycaemia. $\mathrm{HPA}=$ hypothalamic-pituitary-adrenal axis. 


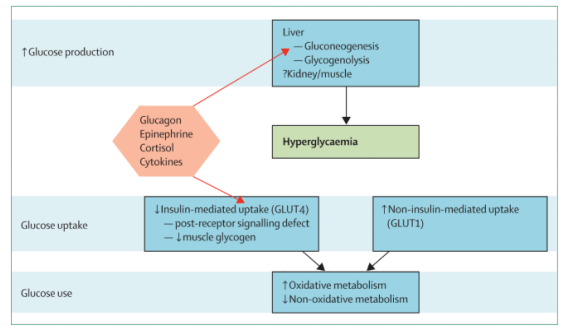

Figure 3. Glucose metabolism in stress hyperglycaemia Stress hyperglycaemia is characterised by increased whole-body glucose uptake, mostly caused by non-insulin-mediated glucose transport via GLUT-1 transporters to body tissues. Insulin-mediated glucose uptake is reduced (insulin resistance), largely due to postreceptor insulin signalling defects that result in reduced GLUT-4-mediated glucose transport in insulin sensitive tissues such as liver, muscle, and fat. Muscle glycogen storage is also reduced. Glucose production is generally up-regulated, mainly a result of unregulated hepatic gluconeogenesis. Finally, once inside a target cell, glucose is oxidised readily but non-oxidative metabolism (predominantly glycogen storage) is impaired. 


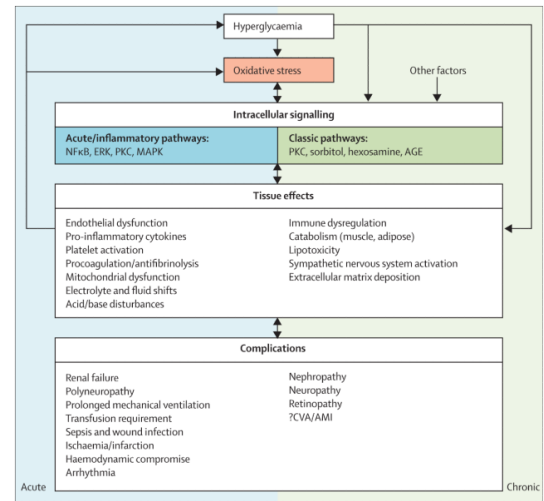

Figure 4. Overlapping mechanisms of harm in hyperglycaemia Mechanisms of harm relate to acute or chronic complications of hyperglycaemia. $\mathrm{NFkB}=$ nuclear factor $\kappa \mathrm{B}$.

ERK = extracellular signal regulated kinase. $\mathrm{MAPK}=$ microtubule associated protein kinase. $\mathrm{PKC}=$ protein kinase $\mathrm{C}$.

$\mathrm{AGE}=$ advanced glycosylation endproducts. $\mathrm{CVA}=$ cerebrovascular accident. $\mathrm{AMI}=$ acute myocardial infarction. 


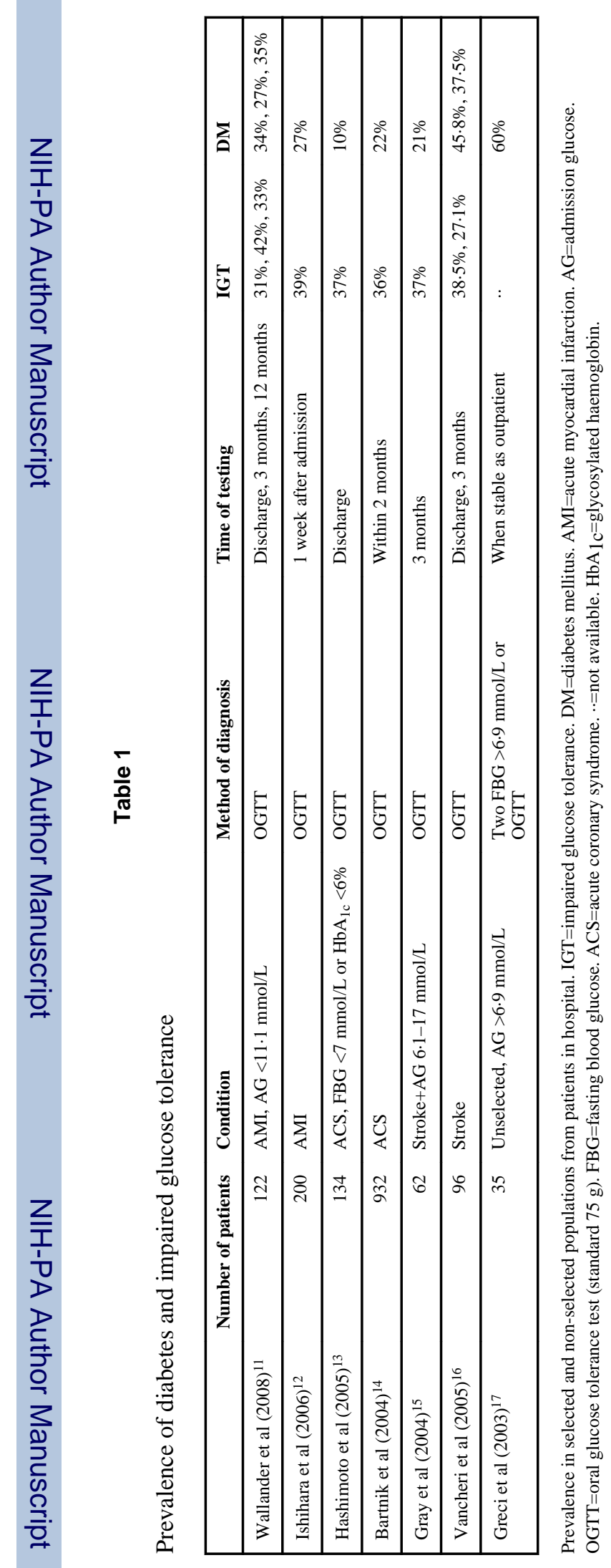

Lancet. Author manuscript; available in PMC 2011 July 27. 